\title{
PENGARUH SUPERVISI DAN MOTIVASI KERJA TERHADAP \\ KUALITAS PENDIDIKAN SEKOLAH DASAR NEGERI DI KECAMATAN MAKASAR JAKARTA TIMUR
}

\author{
DARYANTI*
}

\begin{abstract}
This research aims to find out (1) the influenced of supervision toward work motivation (2) the influenced of work motivation toward education quality (3) the influenced of supervision toward education quality. The research method used is the survey by path analysis. This research was carried out in Kecamatan Makasar East Jakarta. Research findings are outlined as follows (1) there is a direct and significant influenced of supervision toward work motivation (2) there is a direct and significant influenced of work motivation toward education quality (3) there is a direct and significant influenced of supervision toward education quality.
\end{abstract}

Keywords: Supervision, Work Motivation, and Education Quality

\section{PENDAHULUAN}

Pendidikan yang berkualitas mengacu pada proses pendidikan dan hasil pendidikan. Proses pendidikan yang berkualitas apabila seluruh komponen pendidikan terlibat dalam proses pendidikan itu sendiri. Faktor-faktor dalam proses pendidikan adalah berbagai input, seperti bahan ajar, metodologi, sarana sekolah, dukungan administrasi dan sarana prasarana dan sumber daya seperti kepala sekolah, guru dan tenaga kependidikan lainnya serta penciptaan suasana kondusif. Sedangkan kualitas pendidikan dalam konteks hasil pendidikan mengacu pada prestasi yang dicapai oleh sekolah pada setiap kurun waktu tertentu. Selain itu Pendidikan yang berkualitas dilaksanakan secara bertanggung jawab, karena menyangkut masa depan anak, masa depan masyarakat, dan masa depan umat manusia. Pendidikan berkualitas menjadi penting manakala kegiatannya terlaksana dengan baik, terencana dan terarah yang dilaksanakan secara formal maupun non formal. Kegiatan pendidikan formal umumnya dilaksanakan di sekolah dan pendidikan lainnya.

Kepala sekolah sebagai pimpinan sekolah bertanggungjawab atas berjalannya roda organisasi, terutama dalam kegiatan pembelajaran. Sebagai seorang manajer, kepala sekolah mempunyai tugas untuk melaksanakan kegiatan manajemen sekolah yang meliputi perencanaan, pengorganisasian, memimpin/mengarahkan dan mengendalikan, mendayagunakan sumber daya secara optimal, untuk mencapai tujuan yang telah ditetapkan. Sebagai pemimpin, kepala sekolah mempunyai dua dimensi tugas sebagai fungsi dari kepemimpinan, yaitu pencapaian tujuan dan pemeliharaan organisasi. Berdasarkan fenomena dari observasi awal yang dilakukan, kualitas pendidikan Sekolah Dasar Negeri di Kecamatan Makasar Jakarta Timur rendah, terutama dilihat dari kualitas keluaran siswa. Menurut data yang diperoleh, rendahnya nilai Standar Minimal Kelululusan (SKM) yang didapat siswa. Di sisi lain dapat dilihat bahwa pada sekolah dasar khususnya di kecamatan Makasar pada umumnya dalam menentukan kriteria Standar Kelulusan (SKL) sangat rendah.

Hal ini menunjukkan bahwa kualitas pendidikan di Sekolah Dasar Negeri di Kecamatan Makasar Jakarta Timur masih rendah. Tentunya perlu perlu perhatian 
khusus dari para Stakeholder atau pemangku kepentingan di wilayah tersebut agar kualitas pendidikan dapat meningkat. Secara khusus observasi awal menunjukkan pengaruh kepala sekolah dalam peningkatan kualitas pendidikan di sekolah terutama dalam hal supervisi, sangat besar. Selain itu diperlukan motivasi kerja yang tinggi dari kepala sekolah. Berdasarkan permasalahan di atas, penulis ingin mengetahui lebih jelas faktor pemimpin organisasi sekolah yang menjadi penyebab rendahnya kualitas pendidikan, melalu penelitian yang berjudul "Pengaruh supervisi dan motivasi kerja terhadap kualitas pendidikan Sekolah Dasar Negeri di kecamatan Makasar Jakarta Timur".

Kualitas Pendidikan. Edward Sallis (2002:15) menjelaskan pengertian kualitas, "quality can be defined as that wich satisfies and exceed customers' needs and wants. Kualitas dapat didefinisikan sebagai sesuatu yang memuaskan kebutuhan dan keinginan pelanggan. Pengertian tersebut mengandung arti bahwa seseorang atau lembaga sebagai produsen baik barang maupun jasa semestinya memberikan kepuasan dan keinginan para konsumennya. Sejalan dengan pendapat di atas, Dale H. Besterfield, et. al (2003:8) menyatakan pengertian kualitas secara lengkap menyatakan definisi kualitas sebagai berikut:

A more definitive definition of quality is given in ISO 9000:2000. It is defined as the degree to wich a set of inherent characteristics fulfills requirements. Degree means that quality can be used with adjective such as poor, good, and excellent. Inherent is defined as excisting in something, especially as a permanent characteristic. Characteristics can be quantitative or qualitative. Requires is need aor expectation that is started.

Menurut Benjamin Schneider and Susan S. White (2004:9-10) "there are several ways to approach the definition of quality: the philosophical approach, the technical approach and the user based approach. Ada beberapa cara untuk mendekati definisi kualitas: pendekatan filosofis, pendekatan teknis dan pendekatan berbasis pengguna. Selanjutnya dikatakan "philosiphical Approach, this perspective holds that quality is synonymous with innate excellence and that it cannot be defined or anylized further than that". Pendekatan Philosiphical, perspektif ini berpendapat bahwa kualitas adalah sinonim dengan keunggulan bawaan bahwa hal itu tidak dapat ditentukan atau dianalisa lebih jauh dari itu. Kualitas bisa menjadi sebuah keunggulan dari sebuah jasa atau barang yang sudah menjadi ciri dari bentuk layanan ataupun barang kepada konsumen.

Dalam dunia pendidikan, kualitas pendidikan khususnya pada organisasi sekolah maka dinilai dari layanan sekolah tersebut terhadap para pelanggan, baik siswa, orang tua siswa, komite sekolah maupun masyarakat. Terkait dengan hal tersebut menurut Mark M. Davis and Janelle Heineke (2003:296) menjelaskan bahwa : Quality can mean so many different things to different people at different times, it is important to develop a quality vocabulary that will help service managers and workers understand what their customers want and how to consistently meet their needs. Kualitas dapat diartikan banyak hal yang berbeda untuk orang yang berbeda pada waktu yang berbeda, adalah penting untuk mengembangkan kualitas yang akan membantu seorang pimpinan dan juga pekerja memahami apa yang pelanggan inginkan dan bagaimana untuk secara konsisten memenuhi kebutuhan mereka. Pengertian tersebut mengandung makna bahwa kualitas dalam suatu layanan kepada konsumen harus memenuhi kebutuhan para konsumen atau pelanggan.

Lebih lanjut Mark M. Davis and Janelle Heineke (2003:8) layanan kepada pelanggan, diperlukan kriteria yang lebih dikenal dengan "reliability, assurance, tangible, reponsiveness, empathy." Pertama, Reliability sebagai keandalan kemampuan untuk 
memberikan layanan secara akurat, tepat waktu, dan sesuai keinginan. Dalam hal ini pihak yang memberikan layanan dapat memberi kepuasan sesuai dengan yang diharapkan pelanggan dalam hal keaurasian dan ketepan waktu. Ke dua Assurance sebagai jaminan pengetahuan dan kemampuan melayani pelanggan, percaya diri. Pihak pemberi layanan dalam memberikan layanan kepada konsumen atau pelanggan harus mampu memberi jaminan akan layanan yang berkualitas sesuai dengan landasan keilmuan yang memadai. Ke tiga Tangible merupakan penampilan fisik dan tersedianya sarana komunikasi yang memberikan pandangan baik pada pelanggan. Tampilan fisik dapat mempengaruhi pelanggan dalam menentukan kualitas dari layanan. Pihak pemberi layanan yang dapat memberikan layanan yang berkualitas mampu memperhatikan proses terjadinya layanan melalui komunikasi yang baik. keempat Empathy dimana harus memberikan perhatian, memahami, peduli dan memenuhi kebutuhan pelanggan. Pelanggan akan kembali menggunakan jasa atau barang yang diberikan pemberi layanan apabila mereka merasa diperhatikan dalam layanan. Kelima responsiveness merupakan kemampuan untuk membantu pelanggan menyediakan jasa layanan dengan cepat, tanggap dan memberi prioritas sesuai dengan yang diinginkan.

Berdasarkan uraian tentang kualitas pendidikan maka dapat dibuat sintesis yang dimaksud dengan kualitas pendidikan adalah kesesuaian pemberi layanan terhadap pelanggan untuk membantu dan memenuhi kebutuhan dalam menyelesaikan masalahmasalah pelanggan dalam rangka pencapaian tujuan pendidikan. Terdiri dari indikator; reliability (keandalan), assurance (keakuratan), tangible (tampilan fisik), reponsiveness (tanggap), empathy (empati).

Supervisi. Definisi supervisi menurut Rue and Byars (2010:3) adalah : supervision is the first level of management in an organization an is concerned with encouraging the members of a work unit to contribute positively toward accomplishing the organization's goals and objectives. Pengawasan adalah tingkat pertama dari manajemen dalam suatu organisasi yaitu dengan mendorong anggota organisasi untuk memberikan kontribusi positif dalam mencapai tujuan organisasi. Definisi tersebut mengandung arti bahwa supervisi menjadi hal yang utama dalam pengembangan suatu organisasi dari sisi sumber daya manusia dengan mendorong anggota untuk melakukan pekerjaan yang sudah direncanakan dalam rangka pencapaian tujuan. George R. Terry (2005:178) mendefinisikan supervisi sebagai berikut: Supervision is to monitor whether the movement of these organizations are in accordance with the plan or not. Ans supervising the use of resources within the organization to be used effectivellyand efficientlywithout being deviated from the plan. Supervisi adalah kegiatan untuk memantau apakah pergerakan organisasi sesuai dengan rencana atau tidak. Dan mengawasi penggunaan sumber daya dalam organisasi yang akan digunakan secara efektif dan efisien tanpa menyimpang dari rencana. Definisi tersebut mengandung makna bahwa supervisi adalah kegiatan yang dilakukan seorang pimpinan dalam rangka mengoptimalkan sumber daya yan ada dalam organisasi dalam rangka mencapai tujuan yang diharapkan.

Orang yang melakukan kegiatan supervisi ini disebut supervisor. Supervisor adalah seorang yang profesional. Dalam menjalankan tugasnya, ia bertindak atas dasar kaidah-kaidah ilmiah untuk meningkatkan kualitas pendidikan. Sebagaimana dijelaskan Carlene Cassidy and Robert Kreitner (2010:5): Supervisors are an integral part of the management team process. The legal definition of supervisor is "any individual having authority, in the interest of employer, to hire, transfer, suspend, lay off, recall, promote, discharge, assign, reward, or discipline other employees, or responsibly to direct them, or to adjust their grievances, or effectively to recommend such action, if in connection with the foregoing the 
excercise of such authority is not of merely routine or clarical nature, but requires the use of independent judgement." Pengawas merupakan bagian integral dari proses manajemen tim. Definisi hukum pengawas yang memiliki wewenang adalah setiap individu, dalam kepentingan pimpinan, untuk menyewa, mentransfer, menangguhkan, memberhentikan, ingat, mempromosikan, menetapkan, penghargaan, atau untuk pegawai yang disiplin, atau bertanggung jawab untuk mengarahkan mereka, atau untuk menyesuaikan keluhan mereka, atau secara efektif untuk merekomendasikan tindakan tersebut, jika sehubungan dengan hal tersebut pada pelaksanaan kewenangan tersebut tidak semata-mata dilakukan secara rutin atau alami, tetapi membutuhkan penggunaan penilaian yang independen.

Sebagai seorang supervisor tentunya kepala sekolah memiliki tanggungjawab yang besar daam oraganisasi yang dipimpin. Menurut Carlene Cassidy and Robert Kreitner (2010:9-10), tanggungjawab seorang supervisor seperti kepala sekolah di antaranya adalah :

a. Trainer. As a trainer, supervisors teach employees an coworkers new information an skills.

b. Planner. A planner evaluates goals, objectives, and future needs to prepare plans that provide the neccesary resources and action items to archieve success.

c. Scheduler. As a scheduler, a supervisor prepares the schedule to ensure that proper staffing and resources ar available to meet production or customer needs.

d. Motivator. Supervisors also serve as motivators who inspire their employees to perform at their best and archive a common goal.

e. Coach. A coach is a person who guides employees with instruction, feedback and encoragement.

f. Controller. as a controller, a supervisor measures quality and performance.

g. Leader. A leader sets the tone for organization, creates vision, and insipre others to archive.

h. Recruiter. Recruiter assist in indetifying potential job candidates, screening aplications, interviewing and hiring new employees.

Seorang pemimpin memiliki peran sebagai; (1) trainer atau pelatih, dimana supervisor melatih atau mengajari pegawai segala informasi baru, yang keterampilan yang berguna bagi kemampuan kerja pegawai tersebut. (2) perencana. Sebagai perencana, seorang pemimpin memiliki tanggungjawab merencanakan tujuan serta mengevaluasi dalam rangka kebutuhan ke depan mempersiapkan rencana yang menyediakan sumber daya yang diperlukan untuk kesuksesan. (3) sebagai scheduler, supervisor mempersiapkan jadwal untuk memastikan bahwa staf yang tepat dan sumber daya yang tersedia untuk memenuhi kebutuhan pelanggan. (4) motivator. Supervisor atau pengawas juga berfungsi sebagai motivator yang menginspirasi pegawai mereka untuk melakukan yang terbaik. (5) pelatih, seorang pelatih adalah orang yang menuntun pegawai melalui instruksi dan umpan balik sehingga terjadi komunikasi dua arah yang baik. (6) controller. sebagai pengendali, seorang pengawas mengukur kualitas dan kinerja para bawahannya. (7) pemimpin, seorang pemimpin menetapkan jalannya roda organisasi, menciptakan visi, dan lain-lain. (8) perekrut, sebagai seorang perekrut, pimpinan membantu mengidentifikasi calon pegawai potensial, penyaringan aplikasi/lamaran kerja, wawancara dan mempekerjakan pegawai baru. 
Berdasarkan uraian supervisi di atas, maka dapat dibuat sintesiskan bahwa yang dimaksud dengan supervisi adalah serangkaian kegiatan yang bertujuan untuk mengukur penampilan kerja dalam rangka perbaikan ke arah yang lebih baik. Terdiri dari beberapa indikator: 1) Komunikasi pelaksanan supervisi pada guru, 2) berpikir mandiri dan kreatif dalam pelaksanaan supervisi, 3) pengambilan keputusan dalam pelaksanaan supervise guru, 4) membangun tim dan kepemimpinan organisasi sekolah, 5) Pendelegasian pelaksanaan dalam pelaksanaan supervisi, 6) Penggunaan perangkat computer/teknologi, 7) Menjaga emosi dalam pelaksanaan supervisi.

Motivasi Kerja. Newstrom (2007:101) mengatakan motivasi kerja sebagai berikut: Work motivation is the set of internal and external forces that cause an employee to choose a course of action and engage in certain behaviors. Ideally these behaviors will be directed at the achievement of an organizational goal. Motivasi kerja adalah himpunan kekuatan internal dan eksternal yang menyebabkan seorang pegawai untuk memilih tindakan dan terlibat dalam perilaku tertentu. Idealnya perilaku ini akan diarahkan pada pencapaian tujuan organisasi. Pengertian tersebut mengandung arti bahwa seorang yang bekerja memiliki keinginan untuk berkembang terutama kemajuan preatasi kerja sehingga melalui prestasi tersebut dapat membantu organisasi tempat bekerja mencapai tujuannya. Lebih lanjut Newstrom (2007:101) menjelaskan tentang motivasi kerja seseorang :Work motivation is a complex combination of psychological forces within each person, and employers are vitally interested in three elements of it:

a. Direction and focus of the behavior ( positive factor are dependability, creativity, helpfulness, timeliness; dysfunctional factor, are tardiness, absenteeism, withdrawal, and low performance)

b. Level of the effort provided (making full commitment to excellence versus doing just enough to get buy)

c. Persistence of the behavior(repeatedly maintaining the effort versus giving up prematurely)

Motivasi seseorang dalam bekerja menurut Hezberg dalam Fred Luthans (2008:171) yaitu faktor pendorong motivasi (satisfiers) dan faktor hygiene (dissatisfiers). Satisfiers merupakan faktor pendorong motivasi yang jika faktor tersebut ada maka motivasi seseorang akan terdorong. Sebaliknya dissatisfiers bukan merupakan faktor motivasi, sehingga jika dissatisfiers ada maka seseorang akan terganggu.

Robert Kreitner dan Angelo Kinicki (2010:215) menjelaskan teori motivasi McClelland yang dikenal dengan McClelland's Need Theory. Ada tiga kebutuhan menurut McClelland yaitu; Need for achievement (kebutuhan akan prestasi), Need for afiliation (kebutuhan akan hubungan sosial/hampir sama dengan soscialneed-nya Maslow) dan Need for Power (dorongan untuk mengatur). Berdasarkan uraian tentang teori motivasi di atas maka dapat dibuat sintesis yang dimaksud dengan motivasi kerja adalah dorongan ekstrinsik dan intrinsik pada diri seseorang yang bekerja dalam mencapai tingkat usaha, arah, dan kebutuhan yang diharapkan. Terdiri dari beberapa indikator; dorongan untuk melakukan kreativitas kerja, keinginan menolong orang lain, menjalankan tugas dengan tepat waktu, membuat komitmen penuh untuk keunggulan, bekerja dengan sungguh-sungguh, kegigihan perilaku.

\section{METODE}

Penelitian yang dilakukan menggunakan metode penelitian survey dengan pendekatan Path Analysis. Penelitian ini dilakukan di Sekolah Dasar Negeri di 
Kecamatan Makasar Jakarta Timur. Populasi dalam penelitian ini adalah seluruh kepala Sekolah Dasar Negeri di Kecamatan Makasar Jakarta Timur yang berjumlah 80 orang kepala sekolah. Sampel yang akan digunakan dalam penelitian yaitu berjumlah 45 responden. Pengambilan sampel dilakukan dengan cara simple random sampling dengan cara diundi. Teknik analisis data ditampilkan dalam statistik deskriptif dan Infrensial. Analisis deskriptif terdiri atas penyajian data dengan histogram, perhitungan mean, media, modus, simpangan baku dan rentang teoritik. Analisis infrensial (uji hipotesis dengan analisis regresi dan korelasi, tunggal sederhana). Sebelumnya perlu diuji persyaratan analisis data normalitas dan homogenitas.

\section{HASIL PENELITIAN DAN PEMBAHASAN}

\section{Pengaruh Supervisi terhadap Motivasi Kerja}

Berdasarkan hasil uji hipotesis dengan Path Analysis pengaruh supervisi terhadap motivasi kerja didapat 0,64 dengan $a=0,01$ maka 0,64 $>0,01$ berarti pengaruh sangat signifikan. Signifikannya pengaruh langsung supervisi terhadap motivasi kerja dalam penelitian ini menunjukkan bahwa semakin efektif supervisi maka semakin tinggi motivasi kerja, semakin tidak efektif supervisi maka semakin rendah motivasi kerja. Hal tersebut berkaitan dengan beberapa pendapat tentang pengaruh supervisi terhadap motivasi kerja dimana peran supervisor sebagai pelaksana kegiatan supervisi yang berperan memberikan motivasi kerja seseorang. Carlene Cassidy and Robert Kreitner (2010:9-10) menyatakan, supervisors also serve as motivators who inspire their employees to perform at their best and archive a common goal.52 Supervisor atau pengawas juga berfungsi sebagai motivator yang menginspirasi pegawai mereka untuk melakukan yang terbaik. Pendapat tersebut menunjukkan bahwa pelaksanaan supervisi dapat mempengaruhi motivasi kerja seseorang, sebagai contoh dalam pelaksanaan pendidikan, seorang pengawas sekolah yang melaksanakan supervisi terhadap kepala sekolah dengan efektif dan pendekatan yang baik maka dapat memunculkan motivasi kerja kepala sekolah dalam menjalankan roda organisasi sekolah. Selanjutnya pelaksanaan supervisi juga dapat mengukur kerja seseorang termasuk di dalamnya motivasi dalam bekerja seperti dikatakan Dessler (2011:4), "controlling is the task ensuring that activities are providing the desired result". Pengawasan dapat diartikan sebagai seperangkat target yang mengukur kerja dan mengambil tindakan perbaikan apabila diperlukan. pendapat di atas memiliki makna bahwa melalui supervisi, seorang pimpinan dapat mengukur kerja bawahannya sehingga melalui kegiatan supervisi tersebut dapat dilakukan perbaikan maupun peningkatan kerja para bawahan yang didukung motivasi dalam bekerja.

Dengan demikian hipotesis penelitian yang menyatakan terdapat pengaruh langsung supervisi terhadap motivasi kerja terbukti kebenarannya. Dengan kata lain semakin efektif supervisi maka semakin tinggi motivasi kerja.

\section{Pengaruh Motivasi Kerja terhadap Kualtas Pendidikan}

Berdasarkan hasil uji hipotesis dengan Path Analysis pengaruh motivasi kerja terhadap kualitas pendidikan didapat 0,36 dengan $\alpha=0,01$ maka 0,36 $>0,01$ berarti pengaruh sangat signifikan. Signifikannya pengaruh langsung motivasi kerja terhadap kualitas pendidikan dalam penelitian ini menunjukkan bahwa semakin tinggi motivasi kerja maka semakin tinggi kualitas pendidikan, semakin rendah motivasi kerja maka semakin rendah kualitas pendidikan. Hal tersebut menunjukkan pentingnya motivasi kerja para personal sekolah khsusunya kepala sekolah dalam rangka peningkatan kualitas pendidikan. Seperti diketahui bahwa kualitas pendidikan merupakan tujuan pendidikan dan motivasi kerja para personal menjadi salah satu faktor dalam 
peningkatan kualitas pendidikan. Pernyataan tersebut didukung oleh Newstrom (2007:101) yang mengatakan sebagai berikut; Work motivation is the set of internal and external forces that cause an employee to choose a course of action and engage in certain behaviors. Ideally these behaviors will be directed at the achievement of an organizational goal.

Motivasi kerja adalah himpunan kekuatan internal dan eksternal yang menyebabkan seorang pegawai untuk memilih tindakan dan terlibat dalam perilaku tertentu. Idealnya perilaku ini akan diarahkan pada pencapaian tujuan organisasi. Pengertian tersebut mengandung arti bahwa seorang yang bekerja memiliki keinginan untuk berkembang terutama kemajuan preatasi kerja sehingga melalui prestasi tersebut dapat membantu organisasi tempat bekerja mencapai tujuannya. Dengan demikian hipotesis penelitian yang menyatakan terdapat pengaruh langsung motivasi kerja terhadap kualitas pendidikan terbukti kebenarannya. Dengan kata lain semakin tinggi motivasi kerja maka semakin tinggi kualitas pendidikan.

\section{Pengaruh Supervisi terhadap Kualitas Pendidikan}

Berdasarkan hasil uji hipotesis dengan Path Analysis pengaruh supervisi terhadap kualitas pendidikan didapat 0,45 dengan $a=0,01$ maka 0,45 $>0,01$ berarti pengaruh sangat signifikan. Signifikannya pengaruh langsung supervisi terhadap kualitas pendidikan dalam penelitian ini menunjukkan bahwa semakin efektif supervisi maka semakin tinggi kualitas pendidikan, semakin tidak efektif supervisi maka semakin rendah kualitas pendidikan. Hal tersebut berkaitan dengan pentingnya pelaksanaan supervisi dalam rangka peningkatan kualitas pendidikan, karena pada sebuah organisasi sekolah tujuan yang ingin dicapai adalah meningkatnya kualitas pendidikan di sekolah. Sejalan dengan pendapat tersebut Rue and Byars (2010:3), "supervision is the first level of management in an organization an is concerned with encouraging the members of a work unit to contribute positively toward accomplishing the organization's goals and objectives". Pengawasan adalah tingkat pertama dari manajemen dalam suatu organisasi yaitu dengan mendorong anggota organisasi untuk memberikan kontribusi positif dalam mencapai tujuan organisasi. Terkait dengan hal tersebut, dalam konteks pengawasan kualitas pendidikan, maka supervisi oleh pengawas satuan pendidikan antara lain kegiatannya berupa pengamatan secara intensif terhadap proses kegiatan pada lembaga pendidikan, kemudian ditindak lanjuti dengan pemberian feed back, dengan demikian pelaksanaan supervisi akan mendapatkan input dari personal-personal yang disupervisi tersebut. Sehingga input tersebut bisa menjadi bahan evaluasi dalam rangka peningkatan kualitas pendidikan. Supervisor adalah seorang yang profesional. Dalam menjalankan tugasnya, ia bertindak atas dasar kaidah-kaidah ilmiah untuk meningkatkan kualitas pendidikan. Sebagaimana dijelaskan Carlene Cassidy and Robert Kreitner (2010:5): Supervisors are an integral part of the management team process. The legal definition of supervisor is any individual having authority, in the interest of employer, to hire, transfer, suspend, lay off, recall, promote, discharge, assign, reward, or discipline other employees, or responsibly to direct them, or to adjust their grievances, or effectively to recommend such action, if in connection with the foregoing the excercise of such authority is not of merely routine or clarical nature, but requires the use of independent judgement. Pengawas merupakan bagian integral dari proses manajemen tim. Definisi hukum pengawas yang memiliki wewenang adalah setiap individu, dalam kepentingan pimpinan, untuk menyewa, mentransfer, menangguhkan, memberhentikan, ingat, mempromosikan, menetapkan, penghargaan, atau untuk pegawai yang disiplin, atau bertanggung jawab untuk mengarahkan mereka, atau untuk menyesuaikan keluhan mereka, atau secara 
efektif untuk merekomendasikan tindakan tersebut, jika sehubungan dengan hal tersebut pada pelaksanaan kewenangan tersebut tidak semata-mata dilakukan secara rutin atau alami, tetapi membutuhkan penggunaan penilaian yang independen. Dengan demikian hipotesis penelitian yang menyatakan terdapat pengaruh langsung supervisi terhadap kualitas pendidikan terbukti kebenarannya. Dengan kata lain semakin efektif supervisi maka semakin tinggi kualitas pendidikan.

\section{PENUTUP}

Kesimpulan: Dari jabarn hasil perhitungan dan pengujian hipótesis sebagaimana yang dikemukakan pada bab sebelumnya dapat diambil beberapa kesimpulan sebagai berikut :

1. Terdapat pengaruh langsung supervisi terhadap motivasi kerja. Adapun kekuatan korelasi antara supervisi dengan motivasi kerja ditunjukkan dengan perhitungan koefisien korelasi sebesar 0,636 dan nilai koefisien pengaruh sebesar 0,64.

2. Terdapat pengaruh langsung dan signifikan motivasi kerja terhadap kualitas pendidikan. Adapun kekuatan korelasi antara motivasi kerja dengan kualitas pendidikan ditunjukkan dengan perhitungan koefisien korelasi sebesar 0,647 dan nilai koefisien pengaruh sebesar 0,36

3. Terdapat pengaruh langsung supervisi terhadap kualitas pendidikan. Adapun kekuatan antara supervisi dengan kualitas pendidikan ditunjukkan dengan perhitungan koefisien korelasi sebesar 0,679 dan nilai koefisien pengaruh sebesar 0,45

Implikasi: Hasil penelitian yang telah diperoleh ini mempunyai implikasi penting untuk meningkatkan kualitas pendidikan pada berbagai jenjang pendidikanyang ada di DKI Jakarta untuk masa akan datang.

\section{Supervisi}

Penelitian ini menunjukkan bahwa supervisi memiliki pengaruh langsung terhadap motivasi kerja dan kualitas pendidikan. Hasil penelitian ini memberikan pengertian bahwa supervise. Supervisi merupakan bagian terpadu dari program pendidikan yang berbentuk kerja sama dan kelompok. Supervisi yang dilaksanakan secara efektif berpengaruh terhadap motivasi kerja seseorang. Selain itu juga, dalam pelaksanaan supervisi memiliki tujuan mengahhasilkan kualitas pendidikan di sekolah. Oleh karena itu upaya untuk meningkatkan kualitas pendidikan adalah dengan melaksanakan supervisi dengan terprogram, baik dalam hal perencanaan, pelaksanaan dan evaluasi.

2. Motivasi Kerja

Berdasarkan hasil penelitian menunjukkan secara empirik adanya pengaruh motivasi kerja terhadap kualitas pendidikan. Hal ini memberikan pengertian bahwa tinggi rendahnya kualitas pendidikan dapat dilihat dari model supervise yang dilakukan. Upaya yang dapat dilakukan dalam rangka peningkatan kualitas pendidikan adalah melalui motivasi kerja yang tinggi. pengembangan motivasi kerja dapat diperoleh melalui berbagai pelatihan seperti achievement motivation training.

Saran : Adapun saran-saran yang perlu dipertimbnagkan sebagai berikut: 
1. Perlu dilakukan peningkatan efektivitas supervisi melalui berbagai pelatihan peningkatan kompetensi agar kepala sekolah dapat melaksanakan tugas pokok dan fungsi kepala sekolah berdasarkan peraturan yang telah ditetapkan dinas pendidikan.

2. Perlu pelatihan organizatinal behavior untuk para kepala sekolah agar memiliki kemampuan kepemimpinan organisasi

3. Kepala sekolah hendaknya secara aktif melakukan pengembangan diri dalam rangka memberdayakan potensi para guru dan staf agar dapat melaksanakan pekerjaannya dengan baik.

4. Perlu pembinaan melalui berbagai workshop dan seminar untuk para kepala sekolah dengan tujuan meningkatkan kompetensi dalam melaksanakan manajemen sekolah dengan baik

5. Kepada sesama peneliti agar melakukan penelitian-penelitian dengan menggunakan variabel komponen-komponen yang lain untuk mendapatkan informasi yang terbaru mengenai peningkatan etos kerja kepala sekolah, karena hal ini akan sangat mendorong untuk perkembangan mutu pendidikan Indonesia

\section{DAFTAR RUJUKAN}

Arcaro, Jerome S. Quality In Education : An Implementation Handbook, Alih bahasa : Yosal Iriantara (Yogyakarta : Pustaka Pelajar, 2007)

Besterfield, Dale H. Carol Besterfield-Michna, Glen H. Besterfield, Mary BesterfieldSacre, Total Quality Management, Third Edition (New Jersey:Prentice Hall, 2003)

Cassidy, Carlene and Robert Kreitner, Supervision, setting people up for sucsess, (Mason Ohio:South Western Chengage Learning, 2010)

Certo, Samue C. Supervision, concepts and skill-building, (New York : McGraw-Hill Irwin 2010)

Colquitt, Jason A. Jeffery A. Lepine,\& Michael J. Wesson. Organizational Behavior (New York : McGraw-Hill Book Company, 2009)

Gibson, Ivancevich, Donelly and Konopaske. Organization, Behavior, Structure, Processes, thirteen edition. (New York : McGraw Hill, 2010)

Luthans, Fred. Organizational Behavior, ( McGraw Hill International,2011)

Newstrom, John W. Organizational Behavior, twelfth edition, (New York : McGraw Hill, 2007)

Rue, Leslie W. and Lioyd L. Byars, Supervision, key link to productivity, tenth edition, (New York : McGraw-Hill Irwin 2010)

Sallis, Edward. Total Quality Management In Education. (London : Kogan Page. 2002)

Schermerhorn, John R. James G. Hunt, Richard N. Osborn, Mary Uhl-Bien, Organizational Behavior, 11th edition (Pennsylvania:John Wiley \& Sons, 2011),

Schneider, Benjamin and Susan S. White, Service Quality. Research Perspective. (Thousand Oaks, California : Sage Publication, Inc. 2004)

Terry, George R. Principles of Management (Illinois:Richard D. Irwin, 2005) 
Vecchio, Robert P. Organizational Behavior, Core Concept, 6th edition. South Western : Thomson, 2006) 